\title{
VIVÊNCIAS DE MULHERES COM DIAGNÓSTICO DE DOENÇA SEXUALMENTE TRANSMISSÍVEL - DST
}

\author{
Women's Experiences with Sexually \\ Transmitted Disease Diagnosis - STD \\ Experiencias de Muj eres con Diagnóstico de \\ Enfermedad Sexualmente Transmisible - ETS
}

Maria Alix Leite Araújo

Claudia Bastos da Silveira

\section{Resumo}

As doenças sexualmente transmissíveis (DSTs) constituem problema de saúde pública em virtude da sua alta ocorrência. Nas mulheres, o controle é um desafio devido às implicações sociais e de gênero. Esse estudo objetiva conhecer como as mulheres vivenciam o diagnóstico de uma DST e as repercussões da revelação desse diagnóstico ao parceiro sexual. Estudo exploratório-descritivo desenvolvido em uma unidade de saúde de referência para DST de Fortaleza-Ceará. A coleta de dados foi realizada nos meses de fevereiro e março de 2006 e analisada em duas categorias: vivências das mulheres com o diagnóstico da DST e repercussões da revelação do diagnóstico da DST ao parceiro sexual. Constatou-se que a ocorrência de uma DST resulta em impacto negativo para as mulheres em relação ao convívio social e ao relacionamento com o parceiro sexual. 0 aconselhamento desempenha papel fundamental para redução do estresse. Os serviços de saúde devem valorizar os aspectos emocionais relacionados ao diagnóstico da DST, visando contribuir com a melhoria da qualidade de vida das mulheres e na abordagem do parceiro.

Palavras-chave: Doenças Sexualmente Transmissíveis. Saúde da Mulher. Atenção Primária à Saúde. Diagnóstico Clínico.

\section{Abstract}

The sexually transmissible diseases (STD) constitutes problem of public health, because of the high prevalence. For the women, the control is a challenge, because of the social implications and mainly of gender. This objective of this study was to know as the women feel the diagnosis of a STD and the repercussions of the revelation of this diagnosis to the sexual partner. Exploratory-descriptive study developed in a unit of reference health for STD in Fortaleza - Ceará (Brazil). The collection of the data was accomplished the months of February and March in 2006 and the analyzed in two categories: women's experiences with STD diagnosis and the repercussion of the revelation of the STD diagnosis to the sexual partner. It was verified that the occurrence of other STD results a negative impact for the woman in a social relationship with a sexual partner. A word of advice is a fundamental work to reduce the stress. The services of health should valorize the emotional aspects related of the diagnosis other STD, with the vision to contribute with the improvement of the quality of the woman life and approach with the partner.

Keywords: Sexually Transmitted Diseases. Women's Health. Primary Health Care. Diagnosis, Clinical.

\section{Resumen}

Las enfermedades sexualmente transmisibles (ETS) son un grave problema de salud pública, debido a alto prevalecimiento. En las mujeres, el control es un desafío, debido a las implicaciones sociales y de géneros. El objetivo de este estudio es saber como las mujeres viven la diagnosis de una ETS y las repercusiones de la revelación de esta diagnosis a su pareja sexual. Es un estudio exploratorio y descriptivo desarrollado en una unidad de salud de referencia para ETS de Fortaleza - Ceará (Brasil). La cosecha de datos fue realizada en los meses de febrero y marzo de 2006 y analizada en dos categorías: experiencias de mujeres con diagnóstico de ETS y las repercusiones de la revelación a la pareja sexual. Se constató que la ocurrencia de una ETS resulta en impacto negativo para las mujeres en relación al convivió social y al relaciones con la pareja sexual. El acto de aconsejar desempeña papel fundamental para la reducción de estrese. Los servicios de salud deben valorar los aspectos emocionales relacionados al diagnóstico de ETS, visando contribuir para el mejoramiento de la calidad de vida de las mujeres y en el abordaje de la pareja.

Palabras clave: Enfermedades de Transmisión Sexual. Salud de la Mujer. Atención Primaria de Salud. Diagnóstico Clínico. 


\section{INTRODUÇÃO}

As doenças sexualmente transmissíveis (DSTs) acometem a população mundial há tempos e constituem um expressivo problema de saúde pública. Vários fatores interferem para 0 seu controle, tendo, como destaque, o comportamento da população, as questões de gênero, a cultura, os costumes. A estimativa da Organização Mundial de Saúde é de que ocorram 340 milhões de novos casos de DSTs curáveis no mundo e, destas, cerca de 12 milhões no Brasil'.

No Brasil, devido à subnotificação, existe escassez de dados epidemiológicos, o que dificulta um conhecimento real do problema, bem como a elaboração de estratégias para 0 controle. A elevada incidência associada à automedicação torna o problema das DSTs preocupante, pois muitos portadores deixam de ser orientados e tratados adequadamente, favorecendo a sua disseminação ${ }^{2}$. Os portadores têm receio em procurar um serviço de saúde devido ao constrangimento em expor a sua sexualidade, bem como a deficiência na abordagem por parte dos profissionais.

As DSTs são consideradas de alta transcendência pela elevada morbidade, por facilitar a transmissão do vírus HIV, pela possibilidade de transmissão vertical, pelo impacto psicológico que causam aos seus portadores e pelos elevados custos para a economia ${ }^{3}$. São passíveis de prevenção e tratáveis na sua grande maioria, com exceção das doenças causadas por vírus².

Para o desenho de estratégias de prevenção e assistência, alguns fatores devem ser considerados: falta de preparo dos profissionais, que, muitas vezes, tratam os portadores com preconceito e discriminação; irregularidade na disponibilidade de medicamento; e falta de sensibilidade e especificidade nas técnicas laboratoriais ${ }^{4}$. 0 diagnóstico e tratamento tardios podem resultar em complicações para o indivíduo, além do risco de disseminação da doença.

Com o objetivo da quebra imediata da cadeia de transmissão, o Ministério da Saúde instituiu a abordagem sindrômica das DSTs, que tem como finalidade prover, em uma única consulta, diagnóstico, tratamento e aconselhamento adequados ${ }^{4}$. As unidades de saúde precisam estar acessíveis, com disponibilidade de medicação e preservativos.

Quando analisados do ponto de vista dos relacionamentos, muitos são os problemas que enfrentam as pessoas que apresentam um diagnóstico de DST, especialmente as mulheres. 0 aparecimento dessas doenças pode levar ao rompimento de relações, por conta da mágoa de um dos parceiros, pela suspeita ou certeza de ter sido enganado ou traído pelo parceiro infectado 5 .

Por outro lado, as mulheres ficam expostas à contaminação, pois demonstram constrangimento em usar a camisinha ou solicitar seu uso ao parceiro, devido ao medo de perder o companheiro ou, até mesmo, da violência ${ }^{6}$. Essas condições tornam as mulheres vulneráveis a estas doenças, pois muitas, mesmo vivendo um relacionamento monogâmico, tornam-se suscetíveis devido ao comportamento do parceiro ${ }^{7}$ ou à sua inabilidade para dialogar abertamente sobre o problema.

Quando um casal é incentivado a utilizar o preservativo, geralmente levanta uma certa desconfiança e a possibilidade de uma possível traição. Essas situações tornam mais difícil o desenvolvimento de estratégias de prevenção das DSTs/HIV, voltadas para pessoas que vivem relacionamentos estáveis, especialmente as mulheres. A falta de diálogo sobre o exercício da sexualidade entre os casais dificulta a adoção de medidas preventivas, e, muitas vezes, este diálogo só ocorre em momentos conflituosos, como é o caso da presença de uma DST.

\section{0 problema das DSTs em mulheres}

A confirmação do diagnóstico de DST acarreta alterações biológicas e psicológicas em razão dos aspectos culturais e do prejuízo causado ao relacionamento. Por uma série de questões, a revelação ao parceiro sexual causa revolta ${ }^{8}$, o que pode interferir no tratamento devido às recidivas, pois muitos deixam de comparecer à unidade de saúde para avaliação e tratamento adequados 9 .

Por esse motivo, os profissionais de saúde devem realizar 0 aconselhamento, que consiste em um processo de trocas com o cliente, em que o profissional estabelece um clima de respeito e confiança, oferecendo estratégias que façam o mesmo se sentir também responsável pela sua saúde. Visa à adoção de medidas de proteção, além de proporcionar apoio emocional diante do impacto do diagnóstico da infecção $0^{4}$.

0 fato de possuir apenas um parceiro fixo não exime a possibilidade de transmissão das DSTs. Isto porque esse parceiro pode ter contraído a doença no passado ou mesmo manter relação sexual com outras pessoas ${ }^{10}$.

Historicamente, o uso do preservativo sempre esteve relacionado à prostituição, práticas promíscuas e relações extraconjugais, resultando em uma má reputação de seu uso ${ }^{11}$. 0 preservativo, mesmo sendo o método mais eficaz para a redução do risco de transmissão de DST, apresenta taxas de utilização ainda muito baixas. Isto normalmente ocorre por fatores como: relacionamento estável, confiança no companheiro, ausência de relações promíscuas e uso de outro método anticoncepcional ${ }^{4}$.

As desigualdades nas relações de gênero prejudicam a discussão em torno de uma prática sexual mais segura. As mulheres vivem em condições de vulnerabilidade em virtude da submissão ao parceiro, e estes se expõem mais, por acreditarem serem fortes, imunes à doença e terem a infidelidade como fato natural ${ }^{9-12}$. A representação do resultado da DST também pode ser avaliada sob o ponto de vista de gênero. Os homens se lamentam por não terem se prevenido, e as mulheres, mesmo com único parceiro, muitas vezes são acusadas de terem adquirido a doença ${ }^{9}$.

A falta de autonomia das mulheres nas relações conjugais fica evidente no fato de que a decisão em usar o preservativo parte do parceiro. As mulheres recusam-se a tomar a decisão ou mesmo solicitar o seu uso, por medo de colocar em risco o seu casamento e, às vezes, sua sobrevivência. A tentativa de negociação pode ser traduzida como infidelidade por parte dela e agrava-se quando associada a fatores como parceiro fixo, baixa renda e baixa escolaridade ${ }^{13}$.

0 aumento de mulheres infectadas com DST/HIV e as graves conseqüências resultantes dessas patologias, especialmente quando não tratadas, levantaram a necessidade de questionamentos acerca do problema. Acredita-se que 0 
controle e tratamento dessas patologias são possíveis, desde que 0 acesso aos serviços de saúde seja facilitado e haja um atendimento adequado, disponibilidade de medicamentos, preservativos e profissionais da saúde devidamente capacitados para o aconselhamento dos portadores e seus parceiros ${ }^{2}$.

Esse estudo tem por objetivos conhecer como as mulheres vivenciam o diagnóstico de uma DST e as repercussões da revelação ao parceiro sexual. Destaca-se a importância de estudos dessa natureza, pois é fundamental que os profissionais de saúde conheçam e discutam com essas mulheres, durante 0 atendimento, as dificuldades enfrentadas quando diagnosticadas com uma DST, especialmente em relação à revelação ao parceiro sexual, visando prestar apoio emocional e ajudá-las a enfrentar tais situações.

\section{METODOLOGIA}

Trata-se de um estudo exploratório-descritivo, realizado em uma unidade de saúde no município de Fortaleza-CE, referência para atendimento a portadores de DST. A referida unidade tem como missão: garantir atendimento ambulatorial básico e especializado, promover o fortalecimento do nível primário de assistência através do aperfeiçoamento de profissionais, contribuindo para a melhoria das condições de saúde do Ceará14 . A equipe responsável pelo ambulatório e atendimento de DST é composta de enfermeiros, médicos e assistentes sociais.

Os participantes do estudo foram 14 mulheres que estavam em tratamento para DST. A definição dos participantes se deu pela saturação das informações dos depoimentos. Os critérios de inclusão foram: ter diagnóstico de DST, ser maior de 18 anos, não portadora do HIV, estar em acompanhamento na unidade de saúde, ter parceiro no momento do diagnóstico e aceitar participar da pesquisa.

Foram excluídas do estudo as mulheres que estavam no primeiro atendimento, devido ao fato de ainda não ter havido tempo suficiente para revelar o diagnóstico ao parceiro sexual, as que não tinham parceiro no momento do diagnóstico, as menores de 18 anos e as pessoas que se recusaram em participar do estudo.

Os dados foram coletados nos meses de fevereiro e março de 2006. Utilizou-se como técnica de coleta de dados a entrevista estruturada, em que o entrevistador segue um roteiro previamente estabelecido com perguntas predeterminadas $^{15}$. Aplicou-se um pré-teste visando obter aprimoramento e validação do instrumento.

As mulheres foram informadas sobre os objetivos e consultadas se aceitavam participar do estudo. As que aceitaram, assinaram o termo de consentimento livre e esclarecido, que garantia o anonimato e que as permitiam se ausentar a qualquer momento sem nenhum prejuízo para 0 seu atendimento. Foi enviado um ofício à diretoria da unidade de saúde solicitando a realização do estudo, e, após a autorização, deu-se início à coleta dos dados.

As entrevistas foram gravadas após assinatura do termo de consentimento e transcritas na íntegra. As informações coletadas foram classificadas e analisadas em forma de categorias. A categorização classifica elementos constitutivos de um conjunto por diferenciação e, em seguida, por reagrupamento, segundo a analogia, com os critérios definidos ${ }^{16}$. Procedeu-se a análise, agrupando os dados em duas categorias: vivências das mulheres com o diagnóstico da DST e a revelação do diagnóstico ao parceiro sexual.

0 estudo foi submetido à apreciação do Comitê de Ética em Pesquisa da Universidade de Fortaleza, UNIFOR, como regulamenta a resolução 196/96 sobre as diretrizes e normas regulamentadoras de pesquisas envolvendo seres humanos. Para garantir legitimidade e resguardar os sujeitos da pesquisa, foram respeitados os quatro referenciais básicos da bioética: autonomia, não-maleficência, beneficência e justiça ${ }^{17}$.

\section{APRESENTAÇÃO E DISCUSSÃO DOS RESULTADOS}

A faixa etária das 14 mulheres entrevistadas variou entre $18 \mathrm{e}$ 32 anos. Com relação à escolaridade, uma tinha o ensino fundamental completo, três, o ensino fundamental incompleto, e dez o ensino médio completo. No que diz respeito à ocupação, cinco estavam desempregadas, três trabalhavam como domésticas, duas eram vendedoras, uma era telefonista, uma, secretária, uma, almoxarife e uma trabalhava como auxiliar de serviços gerais.

Desde o início da vida sexual, o número de parceiros referido pelas entrevistadas foi o seguinte: cinco tiveram um parceiro sexual, três referiram três parceiros, duas, cinco parceiros, duas, quatro parceiros, uma, dois parceiros, e uma, mais de dez parceiros. No momento das entrevistas, oito moravam com 0 companheiro, seis eram solteiras, mas tinham parceiro fixo.

Onze mulheres moravam em Fortaleza, e três eram procedentes do interior do Estado. Com relação ao diagnóstico das DSTs, duas se encontravam com herpes genital, uma, com sífilis, e onze, com HPV (verruga genital).

\section{Vivências das mulheres com o diagnóstico de DST}

Quando questionadas acerca das vivências com o diagnóstico da DST, as mulheres referiram que apresentaram quadro depressivo, pois achavam que a doença as tiraria do convívio social e que seriam alvo de preconceito. Este achado confrontase com o resultado de um estudo realizado com mulheres HIV positivas que haviam vivenciado o diagnóstico de outra DST. Constatou que apenas o HIV resultou em conflitos emocionais ${ }^{18}$. Por outro lado, estudo com mulheres com HPV no Distrito Federal encontrou que as mesmas vivenciam sentimentos de medo e desconfor to em relação ao diagnóstico ${ }^{8}$.

Percebe-se atualmente nas campanhas de mídia, e, conseqüentemente, nos serviços de saúde e na comunidade em geral, uma maior ênfase nas repercussões pessoais e sociais vivenciadas por pessoas com HIV/AIDS, em detrimento às repercussões psicossociais do diagnóstico das outras DSTs.

0 Ministério da Saúde recomenda a realização do aconselhamento a pessoas com DST. 0 aconselhamento é uma atividade educativa participativa, que prevê a troca de informações entre profissional e usuária, visando ajudá-la a avaliar os seus próprios riscos, tomar decisões e encontrar 
maneiras realistas de enfrentar e lidar com os problemas relacionados às DSTs/HIV/AIDS. Envolve os componentes de orientação/informação, avaliação de riscos e apoio emocional ${ }^{19}$.

Apesar de o Ministério da Saúde recomendar a realização do aconselhamento aos portadores de outras DSTs que não HIV/AIDS, não se percebe por parte dos profissionais a valorização dessa prática nos serviços de saúde. Estes têm dado mais ênfase aos casos em que o aconselhamento contempla situações relacionadas a HIV/AIDS. Observa-se nos depoimentos a seguir que enfrentar o diagnóstico de uma DST também é difícil, traz sofrimento, sérias repercussões e impacto negativo na vida das mulheres.

Seilá, penseique o mundo fosse acabar, que euia me matarou ia morrer. Eu não gosto nem de falar nisso. Pra mim, eu faço que nem existe. É horrivel (A.C.F, 23 anos, HPV).

Eu fiquei arrasada. Eu chorei muito, sou jovem... E tem tantas mulheres que saem transando com tantos homens. Eu tive poucos... Por isso fica difícil de administrar (M.E.H, 24 anos, HPV).

Me senti muito estranha. A gente acha que não vai mais poder conviver com as outras pessoas. Primeiro de tudo éo preconceito. Eu comecei logo a chorar (J.S, 23 anos, HPV).

Entre mulheres que não apresentam muitos parceiros sexuais, é maior a dificuldade de perceber o risco e a situação de vulnerabilidade a que estão submetidas, pois ainda associam as DSTs a mulheres de vários parceiros.

Os depoimentos abaixo mostram que o diagnóstico de uma DST pode trazer inclusive riscos de vida, pois leva as pessoas a apresentarem quadros depressivos e sentimentos negativos. 0 profissional de saúde deve estar sensível e atento às manifestações apresentadas pelas pessoas após o diagnóstico de uma DST, pois pode contribuir de forma positiva para o seu enfrentamento, bem como, quando necessário, encaminhar para um profissional da área de saúde mental, visto que a depressão necessita de cuidados mais especializados.

Ah! Fiquei louca, louca. Eu logo imaginei que não podia mais sair de casa. Eu entrei em depressão. Eu queria ficar deitada, nada agitado, porque pra mim tudo podia aparecer. Me senti diferente de todo mundo. Eu tava achando até que fosse pior que a AIDS. Eu fiquei, bem dizer, sozinha, sem saber como lidar com isso (D.C.S, 20 anos, HPV).

Eu entrei em depressão... (choro), até hoje. Fiquei tão nervosa quando soube, suava... Aíme botaram pra uma psicóloga (M.A, 20 anos, HPV).

... quando você recebe uma notícia dessa, acho que... dá vontade de sumir, é um impacto muito forte. Você pensa que está sendo excluída da sociedade (N.S.0, 20 anos, HPV).

0 diagnóstico de uma DST traz realmente um impacto negativo e afeta especialmente os aspectos emocionais da mulher. Entretanto, algumas parecem enfrentá-la de maneira diferente quando têm auto-estima positiva. Estas, ao longo do tempo, passam a reverter o quadro negativo apresentado pelo problema.

Seilá, horrivel receber essa notícia. Fiqueitriste, mas obomfoi que a partir daíeu passeia me cuidarmais (J.L, 18anos, HPV).
Aí você pensa mil e uma coisas ruins. Mas não é porque você obteve um vírus ou uma bactéria, que você vai ser excluído, você está em tratamento, é uma coisa que pode ter controle. Não pode ter medo de ser feliz, de ter saúde, de ter uma expectativa de vida mais adiante. Essas coisas influenciam muito nos planos da gente. Tem que ter uma cabeça bem feita (N.S.O.S, 20 anos, HPV).

0 atendimento em DST exige dos profissionais de saúde habilidade para lidar com diversas questões, muitas vezes de difícil abordagem. É necessário, também, que estes tenham uma visão holística do cliente e estejam qualificados para fornecer as orientações necessárias, favorecendo um clima de confiança e segurança. Evidencia-se que a orientação é imprescindível para que situações de preconceito e dúvidas possam ser minimizadas.

Os depoimentos abaixo salientam o quanto foi fundamental a orientação e o apoio recebido pelos profissionais de saúde, tornando-se possível, através desse acompanhamento, o acolhimento, esclarecimento de dúvidas, fornecimento de informações e incentivo ao encaminhamento terapêutico adequado.

Primeiro eu fiquei um pouco confusa porque eu pensei que fosse uma coisa mais grave. Mas quando eu vim pra cá, vi que tinha tratamento, que não tinha cura realmente, mas poderia ficar tratando. Eque, por mais que ela fosse tratada, mas se não tivesse aquele controle, poderia aparecer novamente, aí ia me trazer sérios problemas. Aí eu continuei meu tratamento e vou continuar até o dia que for preciso. Esse acompanhamento que eu tive aqui foi essencial pra mim (N.S.O.S, 20 anos, HPV).

... eu nem sabia o que era o HPV, eu via em propaganda, mas não sabia muito. Quando eu ouvia a palavra HPV eu achava que era HIV. Aí depois a enfermeira me explicou 0 que era e eu fiquei mais calma (M.E.H, 24 anos, HPV).

0 aconselhamento adequado pode contribuir para 0 envolvimento da mulher com o tratamento ${ }^{20}$ e está intimamente relacionado com a diminuição do estresse, pois muitos dos sentimentos negativos relativos às DSTs relacionam-se com os preconceitos e estigma que enfrentam seus portadores, muitas vezes infundados cientificamente. Quando orientada adequadamente e recebendo acompanhamento do ponto de vista emocional, a mulher sente-se apoiada e acolhida nas suas demandas.

Entretanto, um dos depoimentos merece destaque por demonstrar o despreparo do profissional ao orientar inadequadamente as formas de transmissão da DST, levando a cliente a permanecer equivocada e possibilitando a manutenção da situação de vulnerabilidade e riscos.

... O médico foi bem sincero. Ele disse que podia ser do vento, de roupa mal lavada de alguém. Isso me confortou um pouco (A.C.S.N, 25 anos, Herpes genital).

Orientações equivocadas por parte dos profissionais podem ocorrer também devido à dificuldade destes em lidar com as questões que envolvem a revelação do diagnóstico da DST. Apesar de bastante divulgadas na mídia nos últimos anos e de os profissionais terem recebido treinamento, estes ainda 
apresentam dificuldade em abordar as DSTs de uma forma mais ampla, ou seja, têm limitações quando os temas são relativos à sexualidade, infidelidade, práticas sexuais, abordagem do parceiro, homossexualidade ${ }^{21}$, especialmente quando a homossexualidade é feminina2121 22 .

Os profissionais demonstram, ainda, um certo desconhecimento com algumas particularidades da doença, o que contribui para a dificuldade de adoção de medidas preventivas por parte destas mulheres, pois não favorece uma reflexão acerca do risco e vulnerabilidade que vivenciam.

0 tratamento das DSTs, de preferência, deve ser ministrado em dose única, visto que o seu objetivo é a quebra imediata da cadeia de transmissão $0^{4}$. Porém, no caso do HPV, doença mais prevalente neste serviço de saúde, fazem-se necessários, na grande maioria das vezes, tempo e empenho dos seus portadores, uma vez que o tratamento geralmente é demorado, levando algumas pessoas a apresentarem dificuldade em dar seguimento, tendo em vista os empecilhos, dentre eles o financeiro para o deslocamento ao serviço de saúde ${ }^{23}$.

Por outro lado, a situação torna-se mais complicada quando essas pessoas são procedentes do interior do estado, pois, como não dispõem de tratamento na sua cidade de origem, necessitam se deslocar várias vezes à cidade de Fortaleza para concluir o tratamento, que, em sua maioria, é demorado, elevando os custos. Estudo realizado em Fortaleza mostrou que, devido à indisponibilidade de atendimento em horários alternativos, os homens com HPV também não conseguem cumprir o tratamento quando estão trabalhando ${ }^{23}$. É o que se evidencia também nos relatos abaixo:

... só é ruim porque tenho que me tratar todo mês e trabalhando... Tenho que vir duas vezes no mês, uma para a enfermeira e a outra pro médico (M.E.H, 24 anos, HPV).

No início eu não queria fazer o tratamento e tudo... porque, sei lá, moro no interior, muito difícil estar pra lá e pra cá (M.E.S.S, 30 anos, HPV).

Percebe-se que as mulheres com DST vivenciam sofrimento, acham que vão ser rejeitadas e têm muita dificuldade em lidar com o diagnóstico. Nesses casos, é inquestionável o papel do profissional de saúde, desde que devidamente capacitado, que possa oferecer explicações claras acerca da importância do tratamento, bem como contribuir para uma reversão do quadro de negatividade. Daí torna-se essencial por parte do profissional o acolhimento e discussão das melhores formas de enfrentamento das dificuldades vivenciadas pelas mulheres portadoras de DST.

\section{Repercussões da revelação do diagnóstico da DST ao parceiro sexual}

Onze mulheres revelaram ao parceiro sexual o diagnóstico da DST, e três ocultaram a informação. Os depoimentos dessas mulheres que omitiram o diagnóstico foram incluídos no estudo, pois a ocultação representa uma reação a ser considerada, uma vez que as mesmas tiveram tempo suficiente para comunicar aos parceiros o diagnóstico. Por outro lado, essa reação representa um fator importante para ser trabalhado pelos serviços de saúde, uma vez que pode representar o medo de sofrer violência por parte do parceiro e demonstra que efetivamente existe dificuldade de diálogo entre os casais.

Segundo as mulheres, a ocultação do diagnóstico ocorreu por receio de seus parceiros culpá-las ou recriminá-las e por medo de serem responsabilizadas pelo problema. É o que se constata nos depoimentos:

Não disse, até hoje ele não sabe. Porque ele é muito cabeça dura... Aí eu tenho que inventar alguma mentira pra dizer a ele (E.F.L, 22 anos, Herpes genital).

Eu não falei por medo, medo da reação dele. Sei lá, do que ele ia pensar de mim (J.L, 18 anos, HPV).

Eu não falei pra ele porque eu morava no interior e sabe como é no interior... Eu acho que se eu falasse, ele não ia me tratar como antes. Ele ia ficar perguntando se eu tinha pegado dele ou de outra pessoa. Então a gente optou por terminar. Mas eu nunca falei pra ele (M.E. H, 24 anos, HPV).

Esses depoimentos reforçam que as mulheres vivenciam situação de vulnerabilidade, mesmo após o diagnóstico da DST, quando não encontram abertura suficiente para discutir com os seus parceiros acerca do problema. Nesse caso, a situação tende a se agravar, considerando que eles precisam comparecer à unidade para avaliação diagnóstica e tratamento, e, por outro lado, mantêm-se a cadeia de transmissão da doença, uma vez que impossibilita também o tratamento de possíveis contactantes do parceiros sexuais. As mulheres temem ser responsabilizadas pelo problema e não conseguem lidar com a possibilidade de infidelidade. A seguir, relatos que reforçam tais situações:

No começo foi muito difícil. Eu fiquei pensando como é que eu ia falar. Como era? Como eram as palavras que eu ia usar pra falar o que é que eu tinha. É difícil. Eu tinha que falar de qualquer jeito. Chamei ele pra conversar, falei que tinha algo sério pra dizer. Ele não deu a mínima atenção. Mas aí depois ele veio e conversamos (M. A, 20 anos, HPV)

Fiquei com medo de falar pra ele porque todo mundo diz que essas coisas se pega de mulher. Fiquei com medo de abrir a boca e ele falar pra mim que eu tinha passado pra ele (M.S.P.S, 25 anos, HPV).

Foi ruim, porque se ele não tivesse, o que ele ia pensar de mim. Eu só tive um parceiro, que é ele (M.E.S.S, 30 anos, HPV).

Com os homens ocorre situação semelhante. Estudo revelou que o processo de comunicação com as parceiras é um dos pontos mais difíceis de serem abordados. 0 sentimento de culpa, a comprovação da traição, o medo de ter contaminado a companheira fazem dessa comunicação um momento ímpar em suas vidas ${ }^{9}$.

0 profissional de saúde pode e deve ajudar as mulheres a revelarem o diagnóstico ao parceiro, provendo-as de argumentos claros e objetivos que facilitem o diálogo. Devem também informar que o fato de o parceiro ser assintomático não significa que o mesmo não é portador da DST. Na prática, essa informação ajuda a aliviar a tensão e o entendimento das formas de manifestação das DSTs, que podem ser totalmente assintomáticas.

Por outro lado, vale a pena salientar que grande parte dos diagnósticos é de HPV, o que dá certas particularidades ao 
problema. 0 HPV é uma doença que pode se manifestar nas formas clínica, subclínica e latente, cujo período de incubação pode ser longo, o que faz com que muitas vezes o próprio portador desconheça estar com o vírus. Por esse motivo, não implica, necessariamente, que houve infidelidade quando um dos parceiros apresenta a doença. Situação semelhante ocorre com o herpes genital.

Os profissionais de saúde devem disponibilizar-se para ajudar na revelação do diagnóstico, oferecer apoio emocional e orientações precisas acerca das formas de transmissão e prevenção, além de favorecer um ambiente acolhedor, com a possibilidade de outros encontros durante este processo.

A reação do parceiro à revelação do diagnóstico variou de atitudes positivas à culpabilidade. É esperado que mulheres de um único parceiro sexual que tenha o resultado negativo para a DST apresentem questionamentos, preocupações e dúvidas acerca da transmissão. Vale salientar o quanto a equipe multiprofissional é essencial para orientar essas mulheres e seus parceiros acerca da possibilidade das formas assintomáticas ou oligoassintomáticas.

Ele falou que não era dele, que não tinha sido ele, que não tinha feito nada. Mas por incrível que pareça, nunca passou nada pra ele. Fez exame, fez de novo, não deu (L.S.L.N, 31 anos, HPV).

Ele veio, fez o exame. Por enquanto, não tinha aparecido nada, só em mim. Aí eu achei estranho. Como é que pode? Se eu peguei dele, em mim apareceu logo e nele, não? (J.S, 23 anos, HPV).

Eu fiquei muito assim... porque as pessoas falaram que esse vírus se pega de relação, né? Aí eu fiquei assim, porque eu nunca tive outro parceiro, o único parceiro foi ele. Ainda fiquei perturbada porque o exame dele não deu nada. Aí eu até perguntei a doutora e ela disse que só pegava de relação. Aí eu perguntei porque no dele não deu nada e o meu deu se eu só transei com ele? Ela disse que com o tempo pode aparecer nele, depende do organismo. Aí eu fiquei mais tranqüila, porque ele pode até pensar que eu... (M.E.S.S, 30 anos, HPV).

Como o diagnóstico da DST envolve a possibilidade de envolvimento de outros(as) parceiros(as) sexual(is), é comum a omissão de informações acerca da infidelidade. Observa-se nos relatos abaixo:

A reação foi que ele colocou a culpa toda pra cima de mim. Como é que eu tinha pegado aquilo? De onde foi? Disse que dele é que não tinha sido. Ele é uma pessoa muito dura mesmo. Ele diz que essas coisas não são pra ele, que ele não pega essas coisas. Aí depois ele veio aqui e conversou com a doutora. Aí que ele foi entender, foi melhorando, porque no começo foi triste, ele ficou com raiva (M.A, 20 anos, HPV).

Sentimentos de raiva e indignação podem estar presentes, especialmente devido à ausência de sintomas no parceiro. Por esse motivo, deve-se sempre evitar enviar o tratamento do parceiro sexual pelo paciente índice, pois se perde a oportunidade de oferecer o aconselhamento, que, como evidenciado neste estudo, é fundamental em todo processo de acompanhamento. No caso específico do HPV, é ainda uma ótima oportunidade para se desmistificarem conceitos errôneos acerca da doença e preservar os aspectos emocionais do relacionamento.

Por outro lado, outros companheiros aceitam com naturalidade o diagnóstico e não apresentam preocupação em identificar o responsável pelo problema. Isso, ao que parece, devese ao fato de os mesmos confiarem nas parceiras. Em um país com diferenças acentuadas nas relações de gênero, cujos homens tendem a ter mais parceiras sexuais que as mulheres ${ }^{24}$, é possível que estes homens já se reconheçam como os possíveis transmissores e, por esse motivo, aceitem o diagnóstico sem problemas.

Normal. Pra ele, assim, é como as coisas da vida. Mas é uma coisa que não tem mais cura, né? Nem eu sei nem ele sabemos como foi (a transmissão). Sei não...(A.C.F, 23 anos, HPV).

Ele reagiu numa boa. Aí eu falei o que a doutora tinha falado, que pegava de relação. Eu fiquei preocupada com que ele ia pensar, mas ele disse que eu não ficasse pensando no que ele ia pensar de mim, não, que ele confiava em mim. Quando eu me juntei com ele, eu era virgem. Aí daí pra cá, pela graça de Deus, eu nunca tive outro homem (M.E.S.S, 30 anos, HPV).

Ao serem indagadas sobre o relacionamento após a revelação do diagnóstico da DST, algumas relataram que não havia afetado a relação.

Normal, acho que nós criamos mais força pra seguir em frente (N.S.O.S, 20 anos, HPV).

Tá bem (o relacionamento), não abalou em nada, não, graças a Deus (M.E.S.S, 30 anos, HPV).

Tá do mesmo jeito, não mudou nada no nosso relacionamento. Acho até que a gente veio se apegar mais por causa disso, um apoiando o outro (J.S, 23 anos, HPV).

Ficou evidente que, logo após a revelação do diagnóstico, essas mulheres parecem viver os momentos mais angustiantes, precisando realmente de apoio emocional para enfrentar a situação. $A$ descoberta da DST e o fato de ter que enfrentar todas as questões que ficam evidentes com o seu diagnóstico trazem sérios desafios à relação. Desconfiança e descrédito passam a fazer parte do cotidiano desses casais que vivenciam essa experiência, alguns chegando até a se separar. Alguns relacionamentos foram abalados, tendo uma delas referido que a separação foi inevitável por não aceitar a infidelidade do companheiro.

Mudou muito nosso relacionamento. Como eu tava magoada com ele, isso foi gerando confusão, briga, aí a gente se separou. Quando voltamos, a gente vê que nunca é a mesma coisa, não há mais confiança. O que ele diz, a maioria das vezes, você acha que não é verdade. Então, fica aquela coisa chata. Ele até já tinha sido casado, tem até um filho. Mas fico pensando... depois de tanto tempo casada, veio aparecer isso... (L.S.L.N, 31 anos, HPV).

Ah, eu não conseguia beijar mais ele, sentia nojo, eu não queria, não conseguia, por mais que quisesse. Aí, não deu mais e a gente se separou (D.C.S, 20 anos, HPV). 
Tem dia que ele tá bom, tem dia que não, fica me tratando mal. Acho que ele está comigo por pena. Não me dá mais atenção como antes. Antes ele chegava, abraçava, beijava. Acho que, pra ele, já tinha era acabado tudo (M.A, 20 anos, HPV).

A sociedade parece aceitar com naturalidade a infidelidade masculina, considerando ser conseqüência da sua masculinidade. Todavia, quando a mulher é a responsável pela traição, está sujeita à condenação ${ }^{12}$. Ao contrário do homem, a mulher costuma se envolver emocionalmente e associar a relação sexual a sentimento ${ }^{18}$.

No que se refere ao uso do preservativo, as mulheres admitiram estar se prevenindo após terem adquirido a doença. Entretanto, cabe ressaltar um depoimento em que a entrevistada revela o poder que seu companheiro tem em decidir sobre a adoção de medidas de prevenção. Percebe-se que, mesmo após o diagnóstico da DST, as mulheres ainda apresentam dificuldade para a adoção de medidas preventivas. Storck et al.? descrevem que questões culturais também são responsáveis pela não-utilização do preservativo entre as pessoas sexualmente ativas.

A gente não usa camisinha em toda relação porque ele não gosta. Às vezes a gente usa, às vezes, não (I.S.C, 19 anos, HPV).

Passei sete anos com meu primeiro namorado, e a gente usava camisinha, mas eu não confiava nele. Com esse agora eu não usava camisinha porque ele não gostava, dizia que não sentia nada. Agora ele ficou com medo e a gente está usando porque a doutora disse que o HPV sempre aparece (M.S.P.S, 25 anos, HPV).

Aqui acolá ele usa camisinha. Eu não peço, não. Quando ele dá na pilha dele, ele usa. Eu não gosto. Não acho confortável, acho bom é no osso mesmo. Uma coisa ruim, sei lá, chega até a esquentar. No começo ele usava, aí depois que passou a confiar, aí deixou de usar (E.F.L, 22 anos, Herpes genital).

A diferença de gênero torna-se evidente quando a mulher vivencia dificuldade em relação ao uso do preservativo, deixando a cargo do homem esta decisão. Por falta de autonomia, ela deixa de aderir ao sexo mais seguro, tornando-se suscetível a contrair doenças ou uma gravidez não planejada, e até não desejada.

Esses depoimentos demonstram o desconforto e a insatisfação das mulheres para fazer uso do preservativo e corroboram com outros estudos que mostram que as principais razões para a sua não utilização são: confiança depositada no

\section{Referências}

1. World Heath Organization-WHO. Sexually transmitted and other reproductive tract infections. A guide to essential practice; 2005.

2. Ministério da Saúde (BR). Coordenação Nacional de DST e Aids. Vigilância Epidemiológica das DST por meio da notificação de casos: uma nova abordagem. DST- J Bras Doencas Sex Transm. 2001; 13(2): 44-7.

3. Saito FJA. DST- saúde reprodutiva e adolescência. Rev Pediatr Moderna 2001 maio; 27(5 ed esp): 25-8. companheiro, prejuízo causado no desempenho do sexo e o fato de o parceiro também não gostar ${ }^{25}$.

Evidencia-se que a revelação do diagnóstico da DST aos parceiros sexuais é uma situação difícil para as mulheres e que pode ter sérias conseqüências. As mesmas vivenciam dificuldade em revelar o diagnóstico ao parceiro sexual por diversos motivos, entre eles o receio da reação, a possibilidade de violência e a comprovação da infidelidade. Isso demonstra uma dificuldade preexistente em manter diálogo no relacionamento, situação que se agrava quando se deparam com uma situação conflitante, como é o diagnóstico de uma DST. Por outro lado, a efetiva adoção de medidas preventivas, ou seja, o uso do preservativo em todas as relações sexuais, é uma realidade ainda distante na vida dessas mulheres.

\section{CONSIDERAÇÕES FINAIS}

0 diagnóstico de uma DST, para a maioria das mulheres, resulta em sentimentos negativos e receio de serem alvo de preconceito e abandono por parte do parceiro sexual e da sociedade e pode acarretar alterações emocionais e psicológicas. Podem-se destacar também os conflitos emocionais e o prejuízo no relacionamento, levando à necessidade de uma abordagem multiprofissional humanizada e holística.

As questões conflituosas geradas pelo diagnóstico da DST podem e devem ser amenizadas durante 0 atendimento nos serviços de saúde. É bastante oportuno que o profissional esteja disponível à escuta, preste apoio emocional e colabore no desenvolvimento do diálogo entre as mulheres e seus parceiros, diálogo este muitas vezes carregado de tensão e conflito. Em se tratando das DSTs, ainda há muito a se fazer para um atendimento holístico, que envolva não somente os aspectos biológicos, mas também questões relativas à sexualidade, infidelidade, práticas sexuais, abordagem ao parceiro etc.

É importante que os serviços de saúde e seus profissionais valorizem também os aspectos emocionais de portadores das outras DSTs que não HIV/AIDS, bem como as repercussões psicossociais desse diagnóstico. Evidenciou-se que uma DST altera o estado psicológico das mulheres, que sentem dificuldade em lidar com a situação no momento do diagnóstico e na revelação ao parceiro sexual.

Os profissionais devem valorizar a escuta verbal e não verbal e oferecer apoio necessário na tentativa de minimizar as angústias e 0 enfrentamento dos problemas que porventura desencadeiem a partir do diagnóstico da doença.

4. Ministério da Saúde (BR). Secretaria de Vigilância em Saúde. Programa Nacional de DST e Aids. Manual de Controle de Doenças Sexualmente Transmissíveis. $4^{0}$ ed. Brasilia (DF); 2006.

5. Passos MRL. DST- Doenças Sexualmente Transmissíveis. Rio de Janeiro (RJ): Cultura Médica; 1995.

6. Vieira NFC, Paiva TCH, Sherlock MSM. Sexualidade, DST/AIDS e adolescência: não quero falar, tenho vergonha. DST-J Bras Doencas Sex Transm. 2001; 13(4): 46-51. 
7.Storck MAL, Saraiva AS, Rodrigues AM, Soares MCCX. Doenças sexualmente transmissíveis no contexto de ditas "donas de casa". DST- J Bras Doenças Sex Transm. 2001; 13(6): 41-8.

8. Primo WQSP, Primo GRP, Cunha FMP, Garrafa V. Estudo bioético da informação do diagnóstico do HPV em uma amostra de mulheres no Distrito Federal. Bioética 2004; 12(2): 33-51.

9. Andrade LS. A trajetória de atendimento dos pacientes masculinos em um ambulatório de DST: relato de experiências. Humanid Cienc Soc. 2002; 4(2): 37-42.

10. Passos MRL, Appolinário MAO, Varela RQ, Pinheiro VMS, Barreto NA, Rodrigues GHS, et al. 0 atendimento de gestantes numa clínica de DST. DST- J Bras Doencas Sex Transm 2003; 15(1): 23-9.

11. Silva AR, Lopes CM, Muniz PT. Blitz do preservativo masculino e feminino: porte, acondicionamento e uso. DST- J Bras Doencas Sex Transm 2002; 14(6): 22-32.

12. Silva CGM. 0 significado de fidelidade e as estratégias para a prevenção da Aids entre homens casados. Rev Saude Publica 2002; 36(4): 40-9.

13. Galvão MRG, Ramos Cerqueira ATA, Ferreira MLSM, Souza LR. Razões do não uso do preservativo masculino entre pacientes com infecção ou não pelo HIV. DST- J Bras Doenças Sex Transm 2002; 14(1): 25-30.

14. Secretaria de Saúde (CE). Serviços de Saúde: unidades da rede estadual. Fortaleza, 2004; [citado 10 set 2005]. Disponível em: http://www.saude.ce.gov.br.

15. Lakatos EM, Marconi MA. Fundamentos de metodologia científica. São Paulo (SP): Atlas; 2001.

16. Rodrigues MSP, Leopardi MT. 0 método de análise de conteúdo: uma versão para enfermeiros. Fortaleza (CE): Fundação Cearense de Pesquisa e Cultura; 1999.

17. Ministério da Saúde (BR). Conselho Nacional de Saúde. Resolução $n^{\circ} 196$ de 10 de outubro de 1996. Dispõe sobre diretrizes e normas técnicas regulamentadoras de pesquisas envolvendo seres humanos. Brasília (DF); 1996.

18. Xavier IM. Doenças sexualmente transmissíveis e o HIV/AIDS: enfermagem discutindo essas ligações perigosas para as mulheres. Rev Bras Enferm 2001 jan/mar; 54(1): 18-26.
19. Ministério da Saúde (BR). Coordenação Nacional de DST/ AIDS. Aconselhamento em DST/HIV/AIDS para a atenção básica. Brasília (DF); 2003.

20. Araújo MAL, Bucher JNFS, Bello PY. Eficácia do aconselhamento para doenças sexualmente transmissíveis em unidades de referência da cidade de Fortaleza, Ceará. DST-J Bras Doenças Sex Transm 2004; 16(1): 31 -7.

21. Silva ACES. 0 programa saúde da família na prevenção de situações de complexidade: o exemplo da AIDS. [dissertação de mestrado. Fortaleza (CE): Faculdade de Medicina/UFC; 2004.

22. Araújo MAL, Galvão MTG, Saraiva MMM, Albuquerque AD. Relação usuária-profissional de saúde: experiência de uma mulher homossexual em uma unidade de saúde de referência de Fortaleza. Esc Anna Nery Rev Enferm 2006 ago; 10(2): 323-27.

23. Araújo MAL, Leitão GCM. Acesso à consulta a portadores de doenças sexualmente transmissíveis: experiências de homens em uma unidade de saúde de Fortaleza, Ceará. Cad Saude Pública 2005 mar/abr; 21(2): 396-403.

24. Araújo MAL, Bucher JSNF, Bello PY. Análise das fichas de atendimento de pacientes com doenças sexualmente transmissíveis das unidades de referência de Fortaleza, 2000 e 2001. DST -J Bras Doenças Sex Transm 2002; 14(4): 18-22.

25. Vieira MAS, Guimarães EMB, Barbosa MA, Turchi MD, Alves MFC, Seixas MSC, et al. Fatores associados ao uso do preservativo em adolescentes do gênero feminino no município de Goiânia. DST -J Bras Doenças Sex Transm 2004; 16(3):77-83.

\section{Sobre as Autoras}

\section{Maria Alix Leite Araújo}

Universidade de Fortaleza - UNIFOR, Fortaleza Ceará.

\section{Claudia Bastos da Silveira}

Hospital Geral de Fortaleza- HGF, Fortaleza Ceará. 